\title{
THE
}

\section{Deriving inherent optical properties from decomposition of hyperspectral non-water absorption}

\author{
Brice K. Grunert \\ Colleen B. Mouw \\ University of Rhode Island, cmouw@uri.edu \\ Audrey B. Ciochetto \\ University of Rhode Island
}

Follow this and additional works at: https://digitalcommons.uri.edu/gsofacpubs

The University of Rhode Island Faculty have made this article openly available.
Please let us know how Open Access to this research benefits you.

This is a pre-publication author manuscript of the final, published article.

Terms of Use

This article is made available under the terms and conditions applicable towards Open Access

Policy Articles, as set forth in our Terms of Use.

\section{Citation/Publisher Attribution}

Grunert, B. K., Mouw, C. B., Ciochett, A. B. (2019). Deriving inherent optical properties from decomposition of hyperspectral non-water absorption. Remote Sensing of Environment, 225, 193-206 .doi: 10.1016/ j.rse.2019.03.004

Available at: https://doi.org/10.1016/j.rse.2019.03.004

This Article is brought to you for free and open access by the Graduate School of Oceanography at DigitalCommons@URI. It has been accepted for inclusion in Graduate School of Oceanography Faculty Publications by an authorized administrator of DigitalCommons@URI. For more information, please contact digitalcommons-group@uri.edu. 

absorption

4

${ }^{2}$ University of Rhode Island, Graduate School of Oceanography, 215 South Ferry Road, Narragansett, RI 02882, USA

22 Keywords: hyperspectral, PACE, inherent optical properties, colored dissolved organic matter, 23 phytoplankton, ocean biogeochemistry 


\section{Abstract}

Semi-analytical algorithms (SAAs) developed for multispectral ocean color sensors have

27 benefited from a variety of approaches for retrieving the magnitude and spectral shape of inherent

28 optical properties (IOPs). SAAs generally follow two approaches: 1) simultaneous retrieval of all

29 IOPs, resulting in pre-defined bio-optical models and spectral dependence between IOPs and 2)

30 retrieval of bulk IOPs (absorption and backscattering) first followed by decomposition into

31 separate components, allowing for independent retrievals of some components. Current algorithms

32 used to decompose hyperspectral remotely-sensed reflectance into IOPs follow the first strategy.

33 Here, a spectral deconvolution algorithm for incorporation into the second strategy is presented

34 that decomposes at-w $(\lambda)$ from in situ measurements and estimates absorption due to phytoplankton

$35\left(\mathrm{a}_{\mathrm{ph}}(\lambda)\right)$ and colored detrital material $\left(\mathrm{a}_{\mathrm{dg}}(\lambda)\right)$ free of explicit assumptions. The algorithm described

36 here, Derivative Analysis and Iterative Spectral Evaluation of Absorption (DAISEA), provides

37 estimates of $\mathrm{a}_{\mathrm{ph}}(\lambda)$ and $\mathrm{a}_{\mathrm{dg}}(\lambda)$ over a spectral range from $350-700 \mathrm{~nm}$. Estimated $\mathrm{a}_{\mathrm{ph}}(\lambda)$ and $\mathrm{a}_{\mathrm{dg}}(\lambda)$

38 showed an average normalized root mean square difference of $<30 \%$ and $<20 \%$, respectively, from

$39 \quad 350-650 \mathrm{~nm}$ for the majority of optically distinct environments considered. Estimated $\mathrm{S}_{\mathrm{dg}}$ median

40 difference was less than $20 \%$ for all environments considered, while distribution of $\mathrm{S}_{\mathrm{dg}}$ uncertainty

41 suggests that biogeochemical variability represented by $S_{\mathrm{dg}}$ can be estimated free of bias. DAISEA

42 results suggest that hyperspectral satellite ocean color data will improve our ability to track

43 biogeochemical processes affiliated with variability in $\mathrm{a}_{\mathrm{dg}}(\lambda)$ and $\mathrm{S}_{\mathrm{dg}}$ free of explicit assumptions. 


\section{Introduction}

Dissolved organic matter (DOM) comprises the largest pool of fixed carbon in the ocean,

46 roughly equivalent to the reservoir of atmospheric $\mathrm{CO}_{2}(\sim 670 \mathrm{Pg} \mathrm{C}$; Hansell et al. 2009; Ogawa et

47 al. 2001). Yet, sources and cycling of DOM in the global ocean remain poorly constrained due to

48 difficulty in assigning origin and tracking changes in composition to a complex mixture of organic

49 compounds composed of up to 20,000 molecular formulas in a sample (Andrew et al. 2013;

50 Mentges et al. 2017; Riedel and Dittmar 2014). A portion of DOM is optically active, colored

51 dissolved organic matter (CDOM), and displays distinct spectral variability between uniquely

52 sourced material, namely terrestrial and marine-derived, and different degradation pathways, such

53 as microbial or photodegradation (Catalá et al. 2016; Danhiez et al. 2017; Helms et al. 2013; Helms

54 et al. 2008; Zhao et al. 2017). Due to its interaction with light, CDOM can be rapidly characterized

55 using optical sensors and is observable from autonomous and satellite platforms (e.g., Siegel et al.

56 2005; Xing et al. 2012). These observations are crucial to adequately model ocean biogeochemical

57 and physical processes due to the influence of CDOM on distribution and spectral quality of light

58 in the water column and heating of the surface ocean (Chang and Dickey 2004; Dutkiewicz et al.

59 2015; Kim et al. 2016).

CDOM absorption $\left(\mathrm{ag}_{\mathrm{g}}(\lambda), \mathrm{m}^{-1} ; \lambda\right.$ denotes wavelength) at visible wavelengths also tracks

61 the spectral shape of $\mathrm{ag}_{\mathrm{g}}\left(\mathrm{S}_{\mathrm{g}}\right)$ and dissolved organic carbon concentration ([DOC], $\left.\mathrm{mg} \cdot \mathrm{L}^{-1}\right)$ in coastal

62 waters where a strong gradient of relatively degraded, terrestrial-derived material and conservative

63 mixing produce a clear, observable signal across unique pools of CDOM (Cory and Kling 2018;

64 Fichot and Benner 2011; Mannino et al. 2014; Stedmon and Markager 2003). This continuous

65 dilution of $\mathrm{ag}(\lambda)$ in coastal waters presents predictive capability of CDOM molecular weight,

66 degradation state and terrestrial biomarkers (e.g., lignin) using $\mathrm{ag}_{\mathrm{g}}(\lambda)$ due to unique spectral features 
67 present in terrestrial material relative to CDOM of marine origin (Fichot et al. 2016; Fichot et al.

68 2013; Helms et al. 2008; Vantrepotte et al. 2015). While these relationships are strong in coastal

69 waters, open ocean waters do not display a consistent relationship between $a_{g}(\lambda), S_{g}$ and [DOC]

70 due to relatively low production rates and strong photodegradation in surface ocean waters (Helms

71 et al. 2013; Nelson et al. 2010). This disconnect between single wavelength estimates of $\mathrm{a}_{\mathrm{g}}(\lambda)$ and

$72 \mathrm{~S}_{\mathrm{g}}$ currently limits our ability to accurately track production and degradation of CDOM across

73 broad spatial scales while also introducing significant uncertainty in estimates of $\mathrm{a}_{\mathrm{ph}}(\lambda)$ and derived

74 products (e.g., chlorophyll-a concentration). Additionally, increasing observations of $\mathrm{a}_{\mathrm{g}}(\lambda)$ have

75 shown that $S_{\mathrm{g}}$ displays significant variability and is capable of characterizing CDOM of unique

76 source, environmental conditions and degradation state (Asmala et al. 2018; Danhiez et al. 2017;

77 Grunert et al. 2018; Helms et al. 2008, 2013). Considering this, it is likely that this parameter

78 contains very useful information regarding food web processes and marine carbon cycling relevant

79 to understanding the balance of the marine DOM carbon reservoir.

Hyperspectral ocean color observations from in situ measurements including flow-through

81 systems and proposed satellite sensors such as the German Aerospace Center's Environmental

82 Mapping and Analysis Program sensor and NASA's Plankton, Aerosol, Cloud and ocean

83 Ecosystem (PACE) sensor provide the potential to observe inherent optical properties (IOP's),

84 including phytoplankton absorption $\left(\mathrm{a}_{\mathrm{ph}}(\lambda), \mathrm{m}^{-1}\right)$, non-algal particulate (NAP) absorption $\left(\mathrm{a}_{\mathrm{d}}(\lambda)\right.$,

$85 \mathrm{~m}^{-1}$ ) and $\mathrm{a}_{\mathrm{g}}(\lambda)$, with greater accuracy across the global ocean. Hyperspectral satellite observations

86 have the proven ability to characterize unique phytoplankton functional groups (Bracher et al.

87 2009; Sadeghi et al. 2012) while flow-through systems have provided an unprecedented view of

88 phytoplankton productivity and physiology at a global scale (Chase et al. 2013; Werdell et al.

89 2013). Additional work including derivative analysis has also shown potential for estimating 
90 pigment concentrations, $a_{g}(\lambda), S_{g}, a_{d}(\lambda)$ and the spectral shape of $a_{d}(\lambda)\left(S_{d}\right.$; Wang et al. 2016; Chase

91 et al. 2017; Vandermeulen et al. 2017; Wang et al. 2018). To date, satellite algorithms use an

92 assumed value or starting point for $S_{d g}$, the combined spectral slope term for $a_{d}(\lambda)$ and $a_{g}(\lambda)$, based

93 on global or regional observations and/or constrain solutions within a pre-defined space (Lee et al.

94 2002; Werdell et al. 2013; Dong et al. 2013; Zhang et al. 2015). These approaches are all made

95 possible by a variety of existing inversion approaches developed for multispectral data outlined by

96 Werdell et al. (2018).

97 Hyperspectral approaches are still scarce but apply bottom-up strategies on in situ $\mathrm{R}_{\mathrm{rs}}(\lambda)$

98 capable of estimating pigment concentrations and separating $a_{g}(\lambda) / S_{g}$ and $a_{d}(\lambda) / S_{d}$ using assumed

99 starting points and lower/upper bounds on variables. Bottom-up strategies provide accurate

100 solutions but result in IOP retrievals that are spectrally dependent on each other (Mouw et al.

$1012015)$. Here, we provide a top-down approach that independently estimates $S_{\mathrm{dg}}, \mathrm{a}_{\mathrm{dg}}(\lambda)$ and $\mathrm{a}_{\mathrm{ph}}(\lambda)$

102 free of explicit assumptions from total non-water absorption $\left(\mathrm{a}_{\mathrm{t}-\mathrm{w}}(\lambda)\right)$ using derivative analysis,

103 iterative spectral evaluation and Gaussian decomposition of total non-water absorption spectra.

104 Beyond estimation of $S_{d g}$ and more accurate spectral retrievals of $a_{p h}(\lambda)$, such a method provides

105 clearer spectral features for the derivation of phytoplankton functional types, including Gaussian

106 fitting and second or fourth derivative analysis of phytoplankton pigments (Chase et al. 2017;

107 Vandermeulen et al. 2017; Wang et al. 2017). We focus on accurate retrieval of $S_{\mathrm{dg}}$ and $\mathrm{adg}_{\mathrm{dg}}(\lambda)$ to

108 represent biogeochemical variability in NAP and CDOM absorption represented by the spectral

109 shape and magnitude of $\mathrm{a}_{\mathrm{dg}}(\lambda)$. Our results suggest the algorithm, Derivative Analysis and Iterative

110 Spectral Evaluation of Absorption (DAISEA), will work well with future top-down hyperspectral 111 inversion approaches. 


\section{2. Methods}

\section{$114 \quad 2.1$ Data}

In situ data were accessed from NASA's SeaWiFS Bio-optical Archive and Storage System

116 (SeaBASS, https://seabass.gsfc.nasa.gov/) on January 12, 2018 (Werdell et al. 2003). We focused

117 our collection on data where $\mathrm{a}_{\mathrm{ph}}(\lambda), \mathrm{a}_{\mathrm{d}}(\lambda)$ and $\mathrm{ag}_{\mathrm{g}}(\lambda)$ were all measured coincidentally on a benchtop 118 spectrophotometer within $10 \mathrm{~m}$ of the surface (Fig. 1). We initially quality controlled each set of 119 absorption spectra by considering if any values were below zero for individual spectra. If the 120 minimum value was more negative than -0.1 , the spectra was discarded; if the value was greater

121 than -0.1 , an offset for the most negative value was applied to the entire spectrum. In doing so,

122 spectral shape was retained while removing poorly defined absorption values that resulted in 123 negative algorithm solutions. We removed any spectra where $S_{\mathrm{dg}}$ was less than $0.004 \mathrm{~nm}^{-1}$, values

124 unrealistic with historic observations and estimates (e.g., Siegel et al. 2002; Wang et al. 2005). 125 Additionally, spectra that had been sampled at a resolution less than $2 \mathrm{~nm}$ were not considered to 126 ensure spectral shape was maintained when downsampling. After removing poor quality spectra, 127 a total of 4,787 spectra remained. These spectra were randomly split into training (n=3,434; Fig. 128 1a) and test datasets ( $n=1,353$; Fig. $1 b)$ so that training spectra accounted for $\sim 75 \%$ of total spectra. 129 All absorption spectra were subsampled to $5 \mathrm{~nm}$ either through direct sub-sampling or linear 130 interpolation to avoid introducing artificial curvature, with the spectral range from $350-700 \mathrm{~nm}$ 131 used (71 data points). Some spectra were not sampled down to exactly $350 \mathrm{~nm}$ but were measured 132 at or below $355 \mathrm{~nm}$ (e.g., 350.7; $\mathrm{n}=79$ ); for these spectra, we extrapolated to $350 \mathrm{~nm}$ using a 133 discretized partial differential equation with an enhanced plate metaphor (D’Errico 2005). Typical 134 uncertainty estimates for spectrophotometer measurements, assessed as differences among 135 triplicate samples, ranged from $\sim 5-10 \%$ relative difference (Mouw, unpublished data). We focused 
136 on $5 \mathrm{~nm}$ spectral resolution here for an assessment of performance relative to the anticipated

137 resolution of PACE.

\section{$138 \quad$ 2.2 DAISEA Algorithm Development} analysis, optimizing the fit of $\mathrm{a}_{\mathrm{dg}}(\lambda)$ through iterative spectral evaluation, then estimating $\mathrm{a}_{\mathrm{ph}}(\lambda)$

142 accompanied by figures illustrating the primary components of each step (Fig. 2). Steps 1-7

143 evaluate $\mathrm{a}_{\mathrm{t}-\mathrm{w}}(\lambda)$ to optimize estimates of $\mathrm{a}_{\mathrm{dg}}(\lambda)$ and $\mathrm{a}_{\mathrm{ph}}(\lambda)$ and Step 8 is a Gaussian decomposition

144 of $\mathrm{a}_{\mathrm{t}-\mathrm{w}}(\lambda)$ using estimated $\mathrm{a}_{\mathrm{dg}}(\lambda)$ and $\mathrm{a}_{\mathrm{ph}}(\lambda)$ with constraints defined below. For a detailed

145 discussion on general algorithm framework and empirical relationships used, we refer the reader

146 to section 4.1.2.

147 Step 1

148 To first parameterize $\mathrm{a}_{\mathrm{dg}}(\lambda)$, the second derivative of $\mathrm{a}_{\mathrm{t}-\mathrm{w}}(\lambda)$ was calculated as:

$$
\frac{d^{2} a_{t-w}(\lambda)}{d \lambda^{2}} \approx \frac{a_{t-w}\left(\lambda_{i}\right)-2 a_{t-w}\left(\lambda_{j}\right)+a_{t-w}\left(\lambda_{k}\right)}{\Delta \lambda^{2}}
$$

149 where $\Delta \lambda$ indicates the wavelength resolution used to measure at-w $(\lambda)$ (here, $5 \mathrm{~nm}$ as described 150 above) and $\Delta \lambda=\lambda_{\mathrm{k}}-\lambda_{\mathrm{j}}=\lambda_{\mathrm{j}}-\lambda_{\mathrm{i}}, \mathrm{j}=\mathrm{i}+1, \mathrm{k}=\mathrm{i}+2$ and $\lambda_{\mathrm{i}}$ is the current wavelength (Tsai and Philpot 1998).

151 Points where the second derivative equals 0 indicate inflection points of the spectrum (Fig. 2a; Lee 152 et al. 2007). In theory, for $\mathrm{a}_{\mathrm{t}-\mathrm{w}}(\lambda)$, these are points where individual phytoplankton pigments least 153 impact the underlying exponential signal and thus are considered as the observed signal most likely 154 representative of $\mathrm{a}_{\mathrm{dg}}(\lambda)$ spectral shape. These points were defined as $\lambda_{d 0}$ and were found by 155 identifying where $\mathrm{d}^{2} \mathrm{a}_{\mathrm{t}-\mathrm{w}}(\lambda)$ was approximately 0 . These points were identified by rounding second 156 derivative values to the median magnitude of the second derivative, which is a function of the 157 magnitude of observed absorption. For example, if the median second derivative was 0.005, a 158 value of 0.0008 at $440 \mathrm{~nm}$ would be considered not zero and not included (rounded to 0.001). A 
159 value of 0.0004 at $450 \mathrm{~nm}$ would be considered zero (rounded to 0.000), $450 \mathrm{~nm}$ would be

160 classified as a $\lambda_{d 0}$ wavelength and the corresponding absorption would be used in Step 2.

161 Step 2

162 Using wavelengths identified in Step 1, an initial exponential expression was fitted 163 following

$$
a_{t-w}\left(\lambda_{d 0}\right)=a_{t-w}\left(\lambda_{0}\right) e^{-S\left(\lambda_{d 0}-\lambda_{0}\right)}
$$

164 where $\lambda_{0}$ is the minimum wavelength in $\lambda_{d 0}$ (Fig. 2b). S derived from Eq. 2 was used as the initial 165 estimate of $S_{d g}$ and $\operatorname{adg}\left(\lambda_{0}\right)$ was estimated at $440 \mathrm{~nm}$ by estimating the relative contribution of $166 \mathrm{a}_{\mathrm{dg}}(440)$ to $\mathrm{a}_{\mathrm{t}-\mathrm{w}}(440)$ using a piece-wise exponential relationship derived from the training dataset 167 as follows:

$$
\% a_{p h}(440)=1.038 e^{-0.9257\left(\frac{a_{t-w}(555)}{a_{t-w}(680)}\right)} \text { where } \frac{a_{t-w}(555)}{a_{t-w}(680)}>0.685
$$

168 or

$$
\% a_{p h}(440)=2.088 e^{-1.946\left(\frac{a_{t-w}(555)}{a_{t-w}(680)}\right)} \text { where } \frac{a_{t-w}(555)}{a_{t-w}(680)} \leq 0.685
$$

169 and

$$
\% a_{d g}(440)=100-\% a_{p h y}(440)
$$

170 Eq. 3 was developed on the entire dataset, and outliers were determined as residuals outside 1.5

171 times the interquartile range $\left(25^{\text {th }}\right.$ and $75^{\text {th }}$ quantiles $)$. After determining outliers, a moving window

172 of $10 \% \mathrm{a}_{\mathrm{ph}}(440)$ contribution to $\mathrm{a}_{\mathrm{t}-\mathrm{w}}(440)$ was used to assess for a significant bias in residuals

173 derived from this relationship. Bias was defined as a median residual value an order of magnitude

174 different (positive or negative) than median residual bias between the relationship and all data

175 points. This threshold indicated a bias for $\mathrm{a}_{\mathrm{ph}}(440)$ contributions greater than $60 \%$, corresponding

176 to an $\mathrm{a}_{\mathrm{t}-\mathrm{w}}(555) / \mathrm{a}_{\mathrm{t}-\mathrm{w}}(680)$ ratio of 0.685 . From this, a new relationship (Eq. 4) was developed to

177 estimate $\mathrm{a}_{\mathrm{ph}}(440)$ percent contribution above $60 \%$ without bias. These equations are discussed 178 further in Section 4.1.2 and figures referenced therein. 
From the previous steps, the spectra for $\mathrm{a}_{\mathrm{dg}}(\lambda)$ was then estimated (Fig. 2b) as follows

$$
a_{d g}(\lambda)=\left(a_{t-w}(440) \cdot \% a_{d g}(440)\right) e^{-S_{d g}(\lambda-440)}
$$

180

181

Step 3

To determine if the $\mathrm{a}_{\mathrm{dg}}(\lambda)$ estimate was acceptable, we compared it to $\mathrm{a}_{\mathrm{t}-\mathrm{w}}(\lambda)$ :

$$
a_{\text {residual }}(\lambda)=a_{t-w}(\lambda)-a_{d g}(\lambda)
$$

If $\mathrm{a}_{\text {residual }}(\lambda)$ was always positive, the previous variables $-\lambda_{0}, \mathrm{a}_{\mathrm{dg}}\left(\lambda_{0}\right), \mathrm{S}_{\mathrm{dg}}-$ were maintained at the current estimated values (e.g., $\lambda_{0}=440 \mathrm{~nm}$; Fig. 2 c). If a residual $(\lambda)$ was negative at any point, the wavelength corresponding to the most negative residual was used as $\lambda_{0}$, and $\mathrm{a}_{\mathrm{dg}}\left(\lambda_{0}\right)=\mathrm{a}_{\mathrm{t}-\mathrm{w}}\left(\lambda_{0}\right)$ to recalculate $\mathrm{adg}_{\mathrm{dg}}(\lambda)$ from

$$
a_{d g}(\lambda)=a_{d g}\left(\lambda_{0}\right) e^{-S_{d g}\left(\lambda-\lambda_{0}\right)}
$$

186

Resulting $\mathrm{a}_{\text {residual }}(\lambda)$ was re-calculated again following Eq. 7 for the new estimated $\mathrm{a}_{\mathrm{dg}}(\lambda)$. This step was repeated until all $\mathrm{a}_{\text {residual }}(\lambda)$ values were positive, with $S_{\mathrm{dg}}$ incrementally adjusted by $+0.0001 \mathrm{~nm}^{-1}$ to a maximum adjustment of $+0.011 \mathrm{~nm}^{-1}$. If a potential solution was not found, $\mathrm{S}_{\mathrm{dg}}$ was then incrementally adjusted by $-0.0001 \mathrm{~nm}^{-1}$ to a minimum adjustment of $-0.004 \mathrm{~nm}^{-1}$. The difference in adjustment and focus on positive adjustment values first is discussed further in Section 4.1.2. If no valid solution was found through this routine, the initial estimate of $\mathrm{a}_{\mathrm{dg}}(\lambda)$ was used; if a valid solution was found, that was the new $\operatorname{adg}_{\mathrm{dg}}(\lambda)$ estimate (e.g., Fig. 2c). At this step, negative residual values were allowed, and accounted for in Step 5. This occurred in 91 of the 1,353 spectra evaluated $(6.7 \%$ of the time).

Step 4

Using the new or initial $\mathrm{a}_{\mathrm{dg}}(\lambda)$ estimate, $\mathrm{a}_{\mathrm{ph}}(\lambda)$ was estimated (Fig. 2d) following

$$
a_{p h}(\lambda)=a_{t-w}(\lambda)-a_{d g}(\lambda)
$$

Step 5

To determine if $\mathrm{a}_{\mathrm{dg}}(\lambda)$ was estimated reasonably well, we considered the ratio of $\mathrm{a}_{\mathrm{ph}}(350): \mathrm{a}_{\mathrm{ph}}(440)$, where a value greater than 1.5 was used to indicate whether a significant portion of the $\operatorname{adg}(\lambda)$ signal was still present in the residuals. While some waters with a significant pigment contribution below $400 \mathrm{~nm}$ (e.g., mycosporine-like amino acids) may have violated this rule, it was generally applicable following discussion in Section 4.1.2. 
If $\mathrm{a}_{\mathrm{ph}}(350): \mathrm{a}_{\mathrm{ph}}(440)$ was greater than 1.5 , a blended estimate of $\mathrm{a}_{\mathrm{dg}}(\lambda)$ was produced by fitting residuals from 350-400 $\mathrm{nm}$ with an exponential model (Fig. 2e) following:

$$
a_{d g_{-} \text {residual }}(\lambda)=a_{\text {residual }}\left(\lambda_{0}\right) e^{-S_{\text {residual }}\left(\lambda-\lambda_{0}\right)}
$$

205 A new estimate of $\operatorname{adg}_{\mathrm{dg}}(\lambda)$, denoted as $\operatorname{addg}_{\mathrm{dg}}(\lambda)$, was created from:

$$
a_{d g 2}(\lambda)=a_{d g}(\lambda)+a_{d g_{-} \text {residual }}(\lambda)
$$

206

A new $S_{d g}$ was re-calculated for $\mathrm{a}_{\mathrm{dg} 2}(\lambda)$ and the next iteration of $\mathrm{a}_{\mathrm{dg}}(\lambda)$ was estimated from:

$$
a_{d g}(\lambda)=\left(a_{t-w}(440) \cdot \% a_{d g}(440)\right) e^{-S_{d g_{-} n e w}(\lambda-440)}
$$

207 The $\operatorname{adg}_{\mathrm{dg}}(\lambda)$ estimated from Eq. 12 was then iteratively evaluated by adjusting $\mathrm{S}_{\mathrm{dg}}$ and assessing

whether $\operatorname{adg}_{\mathrm{dg}}(\lambda)>\mathrm{a}_{\mathrm{t}-\mathrm{w}}(\lambda)$ at any wavelength, within each iteration. If $\mathrm{a}_{\mathrm{dg}}(\lambda)>\mathrm{a}_{\mathrm{t}-\mathrm{w}}(\lambda)$, an offset was calculated by finding the wavelength where $\mathrm{adg}_{\mathrm{dg}}(\lambda)$ was most overestimated following

$$
a_{d g}\left(\lambda_{\text {ind }}\right)=a_{t-w}\left(\lambda_{\text {ind }}\right)-\left[a_{d g}\left(\lambda_{\text {ind }}\right)-a_{t-w}\left(\lambda_{\text {ind }}\right)\right]
$$

210 where $\lambda_{\text {ind }}$ corresponds to the wavelength where $\mathrm{a}_{\mathrm{dg}}(\lambda)$ was most overestimated (maximum 211 positive value from $\left.\mathrm{a}_{\mathrm{dg}}(\lambda)-\mathrm{a}_{\mathrm{t}-\mathrm{w}}(\lambda)\right)$. Eq. 8 was then used to re-calculate $\mathrm{a}_{\mathrm{dg}}(\lambda)$, with $\lambda_{0}=\lambda_{\text {ind }}$ and $212 \mathrm{adg}_{\mathrm{dg}}\left(\lambda_{0}\right)$ equivalent to $\mathrm{a}_{\mathrm{dg}}\left(\lambda_{\text {ind }}\right)$ from Eq. 13. The offset corrects for overestimations, but the 213 application of a new $\lambda_{0}$ with the current $S_{\mathrm{dg}}$ can allow for overestimation at a different $\lambda$. If this 214 step was performed, $\operatorname{adg}_{\mathrm{dg}}\left(\lambda_{0}\right)$ was no longer set to the empirically-derived estimate of $\mathrm{a}_{\mathrm{dg}}(440)$, 215 rather, and $\mathrm{a}_{\mathrm{dg}}\left(\lambda_{0}\right)$ and $\mathrm{S}_{\mathrm{dg}}$ were altered simultaneously to find a solution (i.e., $\mathrm{a}_{\mathrm{dg}}\left(\lambda_{0}\right)$ set to $\mathrm{a}_{\mathrm{t}-\mathrm{w}}(\lambda)$ minus an offset, and $S_{d g}$ to the next iterative slope value). These steps were performed in a step217 wise manner until $\mathrm{a}_{\mathrm{ph}}(350): \mathrm{a}_{\mathrm{ph}}(440)$ was less than 1.5 or until the maximum number of allowable 218 iterations, currently set to 20, was reached (Fig. 2f,g). If 20 iterations were reached without a 219 solution, the final calculated model (from the $20^{\text {th }}$ iteration) was used. This allowed for negative 220 residuals to be included in the subsequent estimate of $\mathrm{a}_{\mathrm{ph}}(\lambda)$, following Eq. 9. However, negative 221 values did not impact the spectral analysis used to identify pigments for fitting in Step 7 and 222 negative values were removed through simultaneous fitting of $\mathrm{a}_{\mathrm{dg}}(\lambda)$ and $\mathrm{a}_{\mathrm{ph}}(\lambda)$ in $\operatorname{Step} 8$, described 223 below, where a constraint of non-negative values on solutions was imposed.

224 Step 6

In Step 6, we identified locations and widths of Gaussian curves in $\mathrm{a}_{\mathrm{ph}}(\lambda)$ derived from Eq. 
227 calculate the second derivative of estimated $\mathrm{a}_{\mathrm{ph}}(\lambda)$ as spectral features were accentuated in the 228 second derivative relative to $\mathrm{a}_{\mathrm{ph}}(\lambda)$ (Fig. $2 \mathrm{~h}$ ). The second derivative was smoothed with a linear

229 Savitzky-Golay filter using a $10 \mathrm{~nm}$ smoothing window. This smoothing reduced the number of

230 features identified that correspond to signal noise. The smoothed second derivative was inverted

231 to allow for identification of local maxima (equivalent to where the first derivative equals 0 ) and

232 direct estimation of Gaussian curves on these spectral features - this is a key distinction between

233 our methodology and published bottom-up approaches where Gaussian width and height are

234 constrained as initial conditions or within a fitting window. Identified peaks were then used as an

235 initial estimate of the number of peaks and each peak's location and width (Fig. 2h,i) with each

236 Gaussian curve modeled following

$$
f(x, \varphi, \mu, \sigma)=\varphi e^{-\frac{(x-\mu)^{2}}{2 \sigma}}
$$

237 where $\sigma(\mathrm{nm})$ is the width of the curve, $\varphi\left(\mathrm{m}^{-1}\right)$ is the height of the Gaussian curve defined as $\varphi=$

$238 \frac{1}{\sigma \sqrt{2 \pi}}$, consistent with Gaussian curve height defined as full width at the half maximum, and $\mu(\mathrm{nm})$

239 is the peak center position. Any Gaussian curves with a $\sigma$ less than $5 \mathrm{~nm}$ were removed at this 240 stage, as these features were fit to noise and not pigments when using a $5 \mathrm{~nm}$ spectral resolution.

241 At this stage, $\varphi$ was scaled to the second derivative requiring re-parameterization of Gaussian curve

242 heights relative to $\mathrm{a}_{\mathrm{ph}}(\lambda)$. Additionally, noisy data where $\sigma>5 \mathrm{~nm}$ can result in more identified 243 peaks than was realistic. These issues were addressed in Step 7.

$244 \quad$ Step 7

For Step 7, Gaussian curves identified in Step 6 were scaled to $\mathrm{a}_{\mathrm{ph}}(\lambda)$. This was done by

246 prioritizing peaks based on their relative prominence, identified as the $\varphi$ determined for each

247 identified peak in Step 6 (scaled to the second derivative). When identified in this manner,

248 pigments that did not overlap, or overlap little, were fitted to $\mathrm{a}_{\mathrm{ph}}(\lambda)$ first, following the assumption 
249 that the majority of the absorption signal in that spectral region belongs to that Gaussian 250 component (e.g., chlorophyll-a peak at $676 \mathrm{~nm}$ was typically prioritized for fitting first due to little

251 overlap with other pigments). From this, $a_{\mathrm{ph}}(\lambda)$ was iteratively fit with each Gaussian curve, the

252 signal from that curve was removed, and the next Gaussian curve was fit to the remaining $\mathrm{a}_{\mathrm{ph}}(\lambda)$

253 signal to get a best approximation of $\varphi$ for each Gaussian curve following

$$
a_{p h_{i}}(\lambda)=a_{p h}(\lambda)-\sum_{i=1}^{n} \varphi_{i} e^{-\frac{\left(x-\mu_{i}\right)^{2}}{2 \sigma_{i}^{2}}}
$$

254 where $\mathrm{n}$ indicates the number of peaks identified for fitting from Steps 6d and 6e (Fig. 2) and $\mu$ 255 and $\sigma$ identified in Step 6 were used for each peak. Due to the additive nature of fitting Gaussian 256 curves, there was potential for some peaks to have a negative height. After estimating an 257 appropriate $\varphi$ for each curve, we filtered out peaks with negative heights and we limited the total 258 possible number of peaks to 16 , although fewer peaks were typically identified (mean=7.7 peaks, 259 s.d.=2.2 peaks). Most Gaussian decomposition schemes assume the presence of $\sim 12$ peaks (e.g., 260 Hoepffner and Sathyendranath 1993; Wang et al. 2016; Chase et al. 2017). These studies have 261 considered similar peak locations with minor differences accounting for a total of 16 unique peak 262 locations in the literature. From this, we assumed if more than 16 peaks were present and all had 263 a positive peak height, some identified peaks were noise or signals not affiliated with 264 phytoplankton pigments that had not been removed in earlier steps. We sorted for likely pigment 265 signals by prominence, using the same method described for peak height previously, and selected 266 the 16 most prominent identified peaks if more than 16 peaks were identified. Next, we used the $267 \sigma, \varphi$ and $\mu$ values identified for each Gaussian curve as input into a least squares Gaussian 268 decomposition model that best fit our initial $\mathrm{a}_{\mathrm{ph}}(\lambda)$ estimate (Eq. 10) with the initial Gaussian curve 269 estimates and fitting constraints described in Step 8 to define an updated set of Gaussian curves 270 (Fig. 2j) following the expression: 


$$
a_{p h}(\lambda)=\sum_{i=1}^{n} \varphi_{i} e^{-\frac{\left(x-\mu_{i}\right)^{2}}{2 \sigma_{i}^{2}}}
$$

271 Step 8

272 Results from Steps 1-7 provided the start point for a combined retrieval of $\mathrm{a}_{\mathrm{dg}}(\lambda)$ and $\mathrm{a}_{\mathrm{ph}}(\lambda)$

273 from $\mathrm{a}_{\mathrm{t}-\mathrm{w}}(\lambda)$. Using the estimate of $\mathrm{a}_{\mathrm{dg}}(\lambda)$ from Steps 1-7 and an estimate for each identified

274 Gaussian curve fitted to $\mathrm{a}_{\mathrm{ph}}(\lambda)$, a least squares fitting approach was performed using the following

275 expression:

$$
a_{t-w}(\lambda)=a_{d g}\left(\lambda_{0}\right) e^{-S_{d g}\left(\lambda-\lambda_{0}\right)}+\sum_{i=1}^{n} \varphi_{i} e^{-\frac{\left(x-\mu_{i}\right)^{2}}{2 \sigma_{i}^{2}}}
$$

276 Analogous to methods used for identifying poorly constrained features that deviate from an

277 underlying exponential signal presented elsewhere (e.g., Massicotte and Markager 2016), the

278 model decomposed $\mathrm{a}_{\mathrm{t}-\mathrm{w}}(\lambda)$ by utilizing a baseline exponential (Eq. 8) accompanied by a pre-

279 defined number of Gaussian components based on previous steps (Eq. 16). This method differs

280 from other Gaussian decomposition methods applied to particulate absorption ( $\left.a_{\mathrm{p}}\right)$, in that those

281 methods typically have a pre-defined number of Gaussian components based on analysis of

282 separate $a_{p h}(\lambda)$ for the respective system (e.g., Chase et al. 2013; Wang et al. 2016). This

283 methodology fits primary pigments with width estimated from spectral features identified in the

284 second derivative of estimated $\mathrm{a}_{\mathrm{ph}}(\lambda)$, allowing for a constrained solution to decomposing $\mathrm{a}_{\mathrm{t}-\mathrm{w}}(\lambda)$

285 while not assuming the presence of any specific types of phytoplankton. Parameters in Eq. 17 were

286 constrained utilizing results from Steps 1-7: $\mathrm{a}_{\mathrm{dg}}\left(\lambda_{0}\right)$ can vary from $0 \mathrm{~m}^{-1}$ to $\mathrm{a}_{\mathrm{t}-\mathrm{w}}\left(\lambda_{0}\right), \mathrm{S}_{\mathrm{dg}}$ can vary by

$287-0.002 \mathrm{~nm}^{-1}$ to $+0.003 \mathrm{~nm}^{-1}$ from the input estimate, Gaussian peak width can vary from input

288 width to 3 times the input width, Gaussian peak height can vary by 0.25 times input height to 3

289 times input height and $\mu$ is fixed at the identified location due to high confidence in the second 
290 derivative analysis. DAISEA output was as follows: $\operatorname{adg}(\lambda)$ was that estimated in Eq. 17, while

$291 \mathrm{a}_{\mathrm{ph}}(\lambda)$ was the difference between observed $\mathrm{a}_{\mathrm{t}-\mathrm{w}}(\lambda)$ and $\mathrm{a}_{\mathrm{dg}}(\lambda)$ from Eq. 17 (Fig. 3). Step 8 ensures

292 coherence between the exponential signal and overlying deviations due to $a_{p h}(\lambda)$ as constrained

293 through Steps 1-7 in a flexible manner, while not assuming that $\mathrm{a}_{\mathrm{ph}}(\lambda)$ can be best parameterized

294 by 6-8 Gaussian curves. Fitting of secondary features was possible but also increases the 295 probability of over-constraining a solution (i.e. less flexibility in adjustments to $\operatorname{adg}_{\mathrm{dg}}(\lambda)$ ).

\subsubsection{Low $\operatorname{aph}(\lambda)$ waters}

We found that waters dominated by $\mathrm{adg}_{\mathrm{dg}}(\lambda)$ were best decomposed by fitting an initial exponential function and adjusting to a realistic solution following Eq. 8, 9 and 13. These cases were identified after Eq. 3 and 4; waters were considered dominated by $\mathrm{a}_{\mathrm{dg}}(\lambda)$ where the ratio of $a_{t-w}(555): a_{t-w}(680)>2.528$ (the empirical value indicating $a_{p h}(440)<10 \%$ of $\left.a_{t-w}(440)\right)$. For these

301 situations, the algorithm opted out of the Gaussian decomposition routine and followed a 302 simplified routine analogous to Steps 2-4, where $S_{\mathrm{dg}}$ was considered equivalent to $\mathrm{S}$ calculated for $303 \mathrm{a}_{\mathrm{t}-\mathrm{w}}(\lambda)$ (Eq. 2), and magnitude was adjusted so that $\mathrm{a}_{\mathrm{dg}}(\lambda) \leq \mathrm{a}_{\mathrm{t}-\mathrm{w}}(\lambda)$. We chose this threshold as 304 forcing Eq. 17 to fit all cases resulted in significantly more error in $S_{d g}$ estimates when $a_{\text {ph }}(440)$ 305 contributed $<10 \%$ of $\mathrm{a}_{\mathrm{t}-\mathrm{w}}(440)$. Above this threshold, using Eq. 17 to fit for $\mathrm{a}_{\mathrm{ph}}(\lambda)$ improved 306 estimates of $\mathrm{a}_{\mathrm{dg}}(\lambda)$ and $\mathrm{S}_{\mathrm{dg}}$ while also providing an estimate of $\mathrm{a}_{\mathrm{ph}}(\lambda)$. The exact value of $10 \%$ may 307 not be an ideal threshold for all datasets but worked well as a threshold here and fit within our 308 presentation scheme. Eq. 3 and 4 are empirical and follow band-ratio techniques used for fitting $309 \mathrm{~S}_{\mathrm{dg}}$ in current semi-analytical schemes (Lee et al. 2009; Matsuoka et al. 2013). Noise in this 310 relationship was explained by variability in the exact shape of $\mathrm{a}_{\mathrm{ph}}(\lambda)$ due to varying phytoplankton 311 composition, physiology and pigment packaging effects (Bricaud and Morel 1986; Bricaud et al. 312 1983; Ciotti et al. 2002; Johnsen et al. 1994) as well as variability in the spectral shape and features 
313 of $\mathrm{ag}_{\mathrm{g}}(\lambda)$ and $\mathrm{a}_{\mathrm{d}}(\lambda)$ (Grunert et al. 2018). As the algorithm is currently optimized for a global

314 approach, users may find that adjusting the empirical values used to initially estimate $\mathrm{a}_{\mathrm{dg}}(440)$ and

315 adjusting the value of 1.5 for the ratio of $\mathrm{a}_{\mathrm{ph}}(350): \mathrm{a}_{\mathrm{ph}}(440)$ (Step 5) for a value more representative

316 of their study region results in better algorithm performance.

$317 \quad$ 2.2.2 Functions

318 To develop DAISEA, we focused on creating a primary, custom Matlab function - daisea,

319 an approach that utilizes derivative analysis and iterative fitting to optimize input spectra used in

320 a least squares Gaussian decomposition scheme fitting an exponential signal and a pre-defined

321 number of constrained Gaussian peaks. DAISEA uses a package of custom sub-functions. This

322 package is freely available via GitHub (https://github.com/bricegrunert/daisea/tree/v1.0.0; DOI:

323 10.5281/zenodo.1306817). Version updates will follow Github conventions. Users are encouraged

324 to use the most recent version for application.

\section{$325 \quad 2.3$ Data Analysis}

326 To assess the performance of DAISEA across a variety of water conditions, we present

327 results as eight different categories based on the percent contribution of $a_{p h}(440)$ relative to $a_{t-}$

328 w(440), with the distribution of spectra within these classes shown in Fig. 1. Classes were defined

329 as the percent contribution $\mathrm{a}_{\mathrm{ph}}$ has to the overall absorption budget at $440 \mathrm{~nm}\left(\% \mathrm{a}_{\mathrm{ph}}(440)\right)$ of $0-10$,

$33010-20,20-30,30-40,40-50,50-60,60-70$, and >70, with $\mathrm{n}=286,257,303,210,146,89,34$ and 28

331 spectra, respectively. This classification scheme emphasizes the relative, not the absolute,

332 contribution of phytoplankton to the overall absorption signal. Thus, waters where $\mathrm{a}_{\mathrm{ph}}(440)$ is the

333 dominant contributor to total absorption are not limited to highly productive waters. In this sense,

334 algorithm performance was not assessed across classic definitions of Case 1 or Case 2 waters

335 (Morel and Prieur 1977). Rather, the only group dominated by coastal and inland waters was 0-10 
$336 \% \mathrm{a}_{\mathrm{ph}}(440)$. It should be emphasized that these categories are only used to present the data within

337 the context of relative contribution of $\mathrm{a}_{\mathrm{ph}}(\lambda)$ and $\mathrm{a}_{\mathrm{dg}}(\lambda)$. Beyond separating $0-10 \% \mathrm{a}_{\mathrm{ph}}(440)$ spectra

338 for fitting using Eq. 2, the algorithm does not analyze spectra differently based on these categories.

339 To determine whether $\mathrm{a}_{\mathrm{ph}}(\lambda)$ or $\mathrm{a}_{\mathrm{dg}}(\lambda)$ was retrievable, we calculated the absolute difference

340 in the opposing metric and compared it to the observed value. For example, if $a_{p h \_o b s}(\lambda)>$

$341 \mid \operatorname{adg}_{\text {dobs }}(\lambda)$-adg_est $(\lambda) \mid$, we consider it retrievable at that wavelength. Within each \% $\mathrm{a}_{\text {ph }}(440)$ group,

342 we summed the total number of instances at each wavelength where $a_{\mathrm{ph}}(\lambda)$ or $\mathrm{a}_{\mathrm{dg}}(\lambda)$ was greater

343 than the absolute difference in the opposing metric and divided by the total number of spectra to

344 get a percent retrievable metric for that $\% \mathrm{a}_{\mathrm{ph}}(440)$ group. In addition to percent retrievable metrics,

345 we calculated Bayes factors $\left(\mathrm{BF}_{10}\right.$, unitless) to assess fit significance (Wetzels and Wagenmakers

346 2012). Bayes factors represent the likelihood that the fitted model adequately represents the data

347 relative to an alternative model. Bayes factors can be interpreted literally, so that $\mathrm{BF}_{10}=2$ means

348 the data are twice as likely to be explained by the fitted model than an alternative model. Here, we

349 used $\mathrm{a} \mathrm{BF}_{10} \geq 3$ as the threshold for significance (Wetzels and Wagenmakers 2012). We also

350 calculated root mean square difference (RMSD), normalized RMSD (NRMSD), bias, mean

351 absolute difference (MAD) and unbiased absolute percent difference (UAPD) using the following

352 expressions:

$$
R M S D=\sqrt{\frac{\sum_{i=1}^{n}\left[\left(x_{i}^{\text {estimated }}\right)-\left(x_{i}^{\text {observed }}\right)\right]^{2}}{n}}
$$

$$
\operatorname{NRMSD}(\%)=\frac{R M S D}{x_{\max }^{\text {observed }}-x_{\min }^{\text {observed }}} \times 100
$$




$$
\text { Bias }=\frac{1}{n} \sum_{i=1}^{n}\left(x_{i}^{\text {estimated }}-x_{i}^{\text {observed }}\right)
$$

$$
M A D=\frac{\sum_{i=1}^{n}\left(\left|x_{i}^{\text {estimated }}-x_{i}^{\text {observed }}\right|\right)}{n}
$$

$$
U A P D(\%)=\frac{\left|x_{\text {estimated }}-x_{\text {observed }}\right|}{0.5\left(x_{\text {estimated }}+x_{\text {observed }}\right)} \times 100
$$

358 3. Results

\section{3.1 DAISEA Performance}

Here, we present the results of DAISEA performance on the test dataset. Across all groups,

$361 \mathrm{a}_{\mathrm{dg}}(\lambda)$ was retrievable $>80 \%$ of the time for wavelengths $<450 \mathrm{~nm}$ (Fig. 4a). For waters where

$362 \operatorname{adg}(\lambda)$ contributed greater than $60 \%$, it was retrievable at a rate of $>80 \%$ for all wavelengths up to

$363650 \mathrm{~nm}$. For $\mathrm{a}_{\mathrm{ph}}(\lambda)$, local maxima in retrieval corresponded to chlorophyll-a absorption peaks

364 ( 440 and $680 \mathrm{~nm}$ within DAISEA), with these wavelengths displaying >80\% retrievability for

365 waters with $\% a_{p h}(440)>10$ (Fig. 4b). Relative difference for $a_{p h}(\lambda)$ and $a_{d g}(\lambda)$ was parameterized

366 as NRMSD and displayed excellent performance for both parameters across most wavelengths and

367 environments. For all conditions except $\% \mathrm{a}_{\mathrm{ph}}(440)>70, \mathrm{a}_{\mathrm{dg}}(\lambda)$ had a mean difference less than

$36820 \%$ for wavelengths from $350-650 \mathrm{~nm}($ Fig. $4 \mathrm{c})$. Mean $\mathrm{a}_{\mathrm{ph}}(\lambda)$ difference was generally less than

$36920 \%$ from 350-650 $\mathrm{nm}$ when $\% \mathrm{a}_{\mathrm{ph}}(440)$ was $>10$ (Fig. 4d). As seen in Fig. 4 and 5, $\mathrm{aph}_{\mathrm{ph}}(\lambda)$ was

370 biased to greater than observed values when it was a non-dominant contributor at $440 \mathrm{~nm}$ and was

371 biased towards values less than observed when it was a dominant contributor at $440 \mathrm{~nm}$, and vice 
372 versa for $\operatorname{adg}_{\mathrm{dg}}(\lambda)$ (Fig. 4e). Mean absolute difference generally decreased as the contribution of $373 \mathrm{a}_{\mathrm{ph}}(440)$ increased (Fig. 4f).

374 The threshold for estimating $\mathrm{a}_{\mathrm{dg}}(\lambda)$ with DAISEA appears to be $\% \mathrm{a}_{\mathrm{ph}}(440)<70$; for these 375 conditions, $a_{d g}(\lambda)$ is estimated with NRMSD $<20 \%$ from 350-650 nm. NRMSD for $a_{p h}(\lambda)$ was $<$ $37620 \%$ for the majority of wavelengths between $400-650 \mathrm{~nm}$ when $\% \mathrm{a}_{\mathrm{ph}}(440)$ was $>10$. This was 377 also consistent when considering the retrievability of $\mathrm{a}_{\mathrm{ph}}(440)$ under different conditions and can 378 be considered as the threshold for estimating $a_{\mathrm{ph}}(\lambda) . \mathrm{S}_{\mathrm{dg}}$ uncertainty increased with increasing 379 contribution of $\mathrm{a}_{\mathrm{ph}}(440)$; however, performance was reasonable across all water conditions and 380 estimates (Table 1). This was also confirmed when considering Bayes factors for fitted models. 381 Overall, $\mathrm{BF}_{10}$ were quite high with $94.0 \%$ of collective model retrievals showing a $\mathrm{BF}_{10}>3$, our

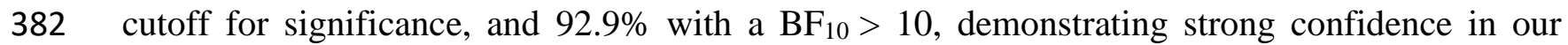
383 approach. The model retrieved $\mathrm{a}_{\mathrm{dg}}(\lambda)$ with slightly better success than $\mathrm{a}_{\mathrm{ph}}(\lambda)$, with $\mathrm{BF}_{10}>3$ for $38499.5 \%$ and $88.5 \%$ of the dataset, respectively. Of models that did not fit observed $\mathrm{a}_{\mathrm{ph}}(\lambda)$ adequately $385(\mathrm{n}=156)$, the majority of poor model fits occurred in waters where $\% \mathrm{a}_{\mathrm{ph}}(440)<20(\mathrm{n}=129)$. Only 3866 model fits were not adequate for $\mathrm{a}_{\mathrm{dg}}(\lambda)$ and distribution across $\% \mathrm{a}_{\mathrm{ph}}(440)$ groups was random.

387 Using the 2.528 threshold applied to $\mathrm{a}_{\mathrm{t}-\mathrm{w}}(440)$ ratios to separate low $\% \mathrm{a}_{\mathrm{ph}}(440)$ did present 388 issues, particularly in the $\% \mathrm{a}_{\mathrm{ph}}(440)$ of 10-20 category. This threshold miscategorized spectra from 389 this category as having $\% \mathrm{a}_{\mathrm{ph}}(440)<10$ in 175 of 257 spectra, resulting in poorly resolved $\mathrm{a}_{\mathrm{ph}}(\lambda)$ 390 for these. This highlights the primary drawback of utilizing empirical relationships and a weakness 391 in our approach. Due to using the 2.528 threshold to separate $\% \mathrm{a}_{\mathrm{ph}}(440)$ contribution, more than 392 half of the $\mathrm{a}_{\mathrm{ph}}(\lambda)$ estimates in the 10-20\% $\mathrm{a}_{\mathrm{ph}}(440)$ group had negative values at wavelengths 393 greater than $650 \mathrm{~nm}$, outside of the chlorophyll-a (Chl) absorption peak at $676 \mathrm{~nm}$ (typically 394 assigned to $680 \mathrm{~nm}$ within the algorithm framework; Fig. 5). While we attempted to account for 
this by using an offset from Eq. 13, moving the location of $\lambda_{0}$ and maintaining $S_{\mathrm{dg}}$ can result in

397 evident in improved estimates of $S_{d g}$ for correctly classified spectra (i.e., spectra where $\% a_{p h}(440)$

was <10). Without a threshold to separate these spectra, attempting to fit $\mathrm{a}_{\mathrm{ph}}(\lambda)$ when it contributed

399 very little resulted in poor algorithm performance, with more spectra poorly fit than with the current approach including a threshold.

402 without any assumptions regarding spectral shape while also independently estimating $\mathrm{a}_{\mathrm{ph}}(\lambda)$. Our

403 results suggest that this is possible across a variety of optical conditions with a reasonable to 404 excellent degree of accuracy, depending on the relative contribution of $\mathrm{a}_{\mathrm{dg}}(\lambda)$. Across the different 405 groups of varying $\mathrm{a}_{\mathrm{ph}}(440)$ contribution, median difference in $\mathrm{S}_{\mathrm{dg}}$ varied from $0.9-17.7 \%$, with

406 third quartile differences ranging from 2.4-39.2\% (Fig. 6a; Table 1). Mean $\mathrm{S}_{\mathrm{dg}}$ observed across all 407 spectra in the test dataset was $0.0147 \mathrm{~nm}^{-1}$ compared to a mean estimated value of $0.0150 \mathrm{~nm}^{-1}$, 408 while median observed and estimated $S_{\mathrm{dg}}$ was 0.0152 and $0.0153 \mathrm{~nm}^{-1}$, respectively. Across 409 individual groups, we evaluated the differences and present anticipated accuracy for $S_{\mathrm{dg}}($ Table 1).

410 For most groups, median difference was $<<0.001 \mathrm{~nm}^{-1}$ and absolute differences affiliated with the $4111^{\text {st }}$ and $3^{\text {rd }}$ quantiles ranged up to -0.0037 and $0.0021 \mathrm{~nm}^{-1}$, respectively, but were typically much

412 smaller. We also considered distribution of differences in $\mathrm{S}_{\mathrm{dg}}$ across all groups and it followed a

413 predominantly normal distribution (data not shown), without an obvious bias between observed 414 and estimated $S_{\mathrm{dg}}$ regardless of $\% \mathrm{a}_{\mathrm{ph}}(440)$ contribution (Fig. 6b).

\section{$415 \quad 3.2$ Consistency in Gaussian features}

416 We considered the accuracy of our Gaussian component locations within DAISEA by 417 comparing to Gaussian component locations identified on observed $\mathrm{a}_{\mathrm{ph}}(\lambda)$ using the same Gaussian 
418 decomposition approach (Fig. 7). Overall, peak locations were quite similar, although DAISEA

419 fitted more peaks (total peaks=10,394; 7.7 peaks/spectra) than for observed $a_{\mathrm{ph}}(\lambda)$ (total

420 peaks $=8,794 ; 6.5$ peaks/spectra). Since $\mathrm{a}_{\mathrm{ph}}(\lambda)$ estimated from the algorithm was derived from the

421 smoothed residuals of $\mathrm{a}_{\mathrm{t}-\mathrm{w}}(\lambda)-\mathrm{a}_{\mathrm{dg} \_ \text {est }}(\lambda)$, the additional noise in the spectra was derived from

422 deviations in $\mathrm{a}_{\mathrm{d}}(\lambda)$ and $\mathrm{a}_{\mathrm{g}}(\lambda)$ not accounted for by a strictly exponential fit. We discuss potential

423 reasons for an increase in fitted peaks in DAISEA output over observed $a_{\mathrm{ph}}(\lambda)$ in Section 4.2 , as

424 well as fitting significantly fewer peaks under our approach than other Gaussian decomposition 425 approaches (e.g., Chase et al. 2013).

426

427 4. Discussion

428 4.1 DAISEA

429 4.1.1 Application

430 As evidenced here and elsewhere, hyperspectral ocean color data provides a means for

431 estimating more variables in a less constrained manner (Bracher et al. 2009; Dierssen et al. 2015;

432 Uitz et al. 2015; Vandermeulen et al. 2017; Wang et al. 2017). Global variability in water optical

433 properties is significant yet the non-uniqueness of $\mathrm{R}_{\mathrm{rs}}(\lambda)$ hampers consistent interpretation across 434 both empirical and semi-analytical methods (Werdell et al. 2018 and references therein). Previous 435 concepts for working around this issue, particularly in light of multispectral limitations, have 436 included screening $\mathrm{R}_{\mathrm{rs}}(\lambda)$ to most likely cases based on optical water types, non-linear spectral 437 optimization, linear matrix inversion, bulk inversion, ensemble inversion and spectral 438 deconvolution (Brando et al. 2012; Hieronymi et al. 2017; Mélin and Vantrepotte 2015; Trochta 439 et al. 2015; Werdell et al. 2018). These approaches are broadly defined as bottom-up and top-down 440 strategies (Mouw et al. 2015), where bottom-up strategies simultaneously solve for all parameters 
441 while top-down strategies allow for independent retrieval of absorbing and scattering constituents $442\left(\mathrm{a}\right.$ and $\left.\mathrm{b}_{\mathrm{b}}\right)$.

443 Current hyperspectral approaches capable of estimating $\mathrm{a}_{\mathrm{ph}}(\lambda), \mathrm{a}_{\mathrm{d}}(\lambda)$ and $\mathrm{a}_{\mathrm{g}}(\lambda)$ operate with

444 bounded ranges and relatively defined pigment locations within a bottom-up framework using

$445 \mathrm{R}_{\mathrm{rs}}(\lambda)$. Notably, Chase et al. (2017) provide a global approach that performs quite well on in situ 446 reflectance data through the use of assumed starting points for IOP's based on global means,

447 Gaussian decomposition of $\mathrm{a}_{\mathrm{ph}}(\lambda)$ using constrained Gaussian curves and lower and upper bounds

448 imposed on all IOP's. Here, we developed a hyperspectral decomposition approach, DAISEA, 449 suitable for a top-down inversion strategy analogous to spectral deconvolution approaches 450 developed for multispectral data (e.g., QAA; Lee et al. 2002; Werdell et al. 2018). Within 451 DAISEA, spectral shapes and features of $\mathrm{a}_{\mathrm{dg}}(\lambda)$ and $\mathrm{a}_{\mathrm{ph}}(\lambda)$ are not assumed but identified through 452 derivative analysis and comparing retrieved spectra to anticipated thresholds. This provides a 453 means for estimating the spectral shape of $\operatorname{adg}(\lambda)$ and phytoplankton pigment identification free of 454 explicit assumptions while also limiting retrievals based on a suitable signal-to-noise ratio (i.e., 455 the algorithm only fits primary spectral features after spectral smoothing with a Savitzky-Golay 456 filter). DAISEA is anticipated to pair well with future inversion schemes designed to work with 457 hyperspectral $\mathrm{R}_{\mathrm{rs}}(\lambda)$ and flow-through $\mathrm{a}_{\mathrm{t}-\mathrm{w}}(\lambda)$ datasets (e.g., Twardowski and Tonizzo 2018).

458 Top-down approaches have been used to retrieve IOP's in an independent manner in a 459 variety of aquatic environments (Mouw et al. 2015). We demonstrated that DAISEA works quite 460 well for in situ absorption datasets. The algorithm does not currently perform well with top-down 461 inversion strategies designed for multispectral data due to relatively high error in estimating at462 w(350). This is a short-coming of our approach, but future top-down hyperspectral inversion 463 approaches are expected to have minimal error and bias across the full spectral range of PACE 
464 (350-800 nm) (Twardowski and Tonizzo 2018). While it is not possible at this time to fully assess

465 the compatibility of DAISEA with these developing approaches, early indications suggest that

466 spectral accuracy of $\mathrm{a}_{\mathrm{ph}}(\lambda)$ and $\mathrm{a}_{\mathrm{dg}}(\lambda)$ could be quite reasonable and in-line with error attached to

467 current approaches (Chase et al. 2017; Wang et al. 2018). Additionally, we did not pursue

468 separation of $\mathrm{a}_{\mathrm{d}}(\lambda)$ and $\mathrm{a}_{\mathrm{g}}(\lambda)$ as current methods for separating within a top-down scheme rely on

469 empirical approaches. Independent approaches for separating these features are currently being

470 considered for future work. Considering the accuracy of estimating $S_{d g}$ with DAISEA (Table 1)

471 and minimal additional uncertainty in separating $\mathrm{a}_{\mathrm{dg}}(\lambda)$ into $\mathrm{a}_{\mathrm{d}}(\lambda)$ and $\mathrm{a}_{\mathrm{g}}(\lambda)$ in future work $(5-10 \%)$,

$472 \mathrm{~S}_{\mathrm{g}}$ could feasibly be retrieved with a median difference of $0.001-0.002 \mathrm{~nm}^{-1}$ across most optical

473 conditions. This would provide an adequate resolution for estimating CDOM source, production

474 and degradation processes as characterized in a variety of in situ studies.

\section{4.1.2 General framework and empirical relationships}

476 The general premise of DAISEA is that $a_{\mathrm{dg}}(\lambda)$ can be accurately modeled using an

477 exponential model and that deviations from this exponential model are solely due to $a_{p h}(\lambda)$. There

478 are alternate explanations for both of these assumptions (e.g., Cael and Boss 2017; Catalá et al.

479 2016); however, there is biogeochemical significance in $S_{d g}$, while phytoplankton would

480 presumably produce the largest deviation from an exponential signal as observable from satellite

481 ocean color data. Beyond these basic assumptions, we also considered the relationship between

$482 \mathrm{a}_{\mathrm{dg}}(\lambda)$ and $\mathrm{a}_{\mathrm{ph}}(\lambda)$ within a theoretical framework (Fig. 8). Based on this framework, it is important

483 to recognize how varying contributions of each component will inherently lead to specific biases.

484 For example, $S_{350: 400}$ fitted to $a_{t-w}(\lambda)$ where $a_{p h}(\lambda)$ contributes will result in lower slope values due

485 to the higher contribution of $\mathrm{a}_{\mathrm{ph}}(\lambda)$ at $400 \mathrm{~nm}$ relative to $350 \mathrm{~nm}$. This is why we increased 486 estimates of $S_{d g}$ first, then alternated to decreasing $S_{d g}$, as an exponential fit of $a_{t-w}(\lambda)$ will produce 
487 lower $\mathrm{S}$ values when $\mathrm{a}_{\mathrm{ph}}(\lambda)$ contributes to the signal. Finding where the second derivative of at$488{ }_{\mathrm{w}}(\lambda)$ equals 0 and fitting an exponential at these points minimizes this impact (essentially "cutting 489 through" primary pigment features for a least squares fit); however, there was still a consistent 490 bias towards lower $\mathrm{S}_{\mathrm{dg}}$ values as $\mathrm{a}_{\mathrm{ph}}(440)$ contribution increased, as expected. The general 491 framework illustrated in Fig. 8 is also the justification for setting a ratio of 1.5 to $\mathrm{aph}_{\mathrm{ph}}(350): \mathrm{a}_{\mathrm{ph}}(440)$; 492 when the residual used to estimate $\mathrm{a}_{\mathrm{ph}}(\lambda)$ had a ratio higher than this, it was almost always 493 indicative of a significant portion of the $\mathrm{a}_{\mathrm{dg}}(\lambda)$ signal remaining in the residual used to calculate $494 \mathrm{aph}(\lambda)$.

In short of independent variables to validate each component of interest, some explicit 496 assumptions are required within any algorithm framework. Here, we chose to limit our solutions 497 by constraining initial $\mathrm{a}_{\mathrm{dg}}(440)$ estimates by the empirical relationship between $\mathrm{a}_{\mathrm{t}-\mathrm{w}}(555) / \mathrm{a}_{\mathrm{t}-\mathrm{w}}(680)$ 498 and $\% \mathrm{a}_{\mathrm{ph}}(440)$ from the training dataset (Fig. 9a) and a theoretical ratio of 1.5 for $499 \mathrm{a}_{\text {residual }}(350) / \mathrm{a}_{\text {residual }}(440)\left(\right.$ Eq. 7) to determine whether the contribution of $\mathrm{a}_{\mathrm{dg}}(\lambda)$ to $\mathrm{a}_{\mathrm{t}-\mathrm{w}}(\lambda)$ from $500 \quad 350-400 \mathrm{~nm}$ had been reasonably estimated and removed. These relationships do not explicitly 501 dictate the final product, but guide the algorithm to reasonable estimates, at which point fitting is 502 not constrained by these specific values. They do, however, leave an impact on how results are 503 constrained. As we discussed previously, empirical relationships can often fall short of their 504 intended accuracy. Despite a similar optical and geographical distribution between the training and 505 test datasets (Fig. 1), the piece-wise exponential relationship derived from the training dataset to 506 predict $\% \mathrm{a}_{\mathrm{ph}}(440)\left(\mathrm{r}^{2}=0.91, \mathrm{RMSD}=0.068\right.$ for fitted points $)$ did not predict the same relationship 507 nearly as well for the test dataset $\left(r^{2}=0.58, \mathrm{RMSD}=0.110\right.$; Fig. $\left.9 \mathrm{~b}\right)$. We considered sensitivity to 508 this empirical relationship on the test dataset. By using a single exponential expression fitted to 509 the test dataset (data points in Fig. 9b), with a value of 0.779 instead of 1.038 and -0.5834 instead 
510 of -0.9257 in Eq. 3, NRMSD fell below $6 \%$ for all wavelengths, with higher values in the UV and

511 lower at longer wavelengths (data not shown). However, the number of Gaussian curves fitted

512 within the algorithm were different for $17 \%$ of spectra, with nearly all instances fit with one fewer

513 Gaussian curves. This suggests that the algorithm is relatively robust across datasets but does 514 exhibit significant sensitivity to empirical values.

$515 \quad$ We adjusted the theoretical value of 1.5 to lower values as a stricter threshold for removing 516 a residual $\mathrm{a}_{\mathrm{dg}}(\lambda)$ signal from the estimate of $\mathrm{a}_{\mathrm{ph}}(\lambda)$ derived from Eq. 9. Algorithm results did not

517 significantly change with values less than 1.5; however, spectra that contain pigments below 400 $518 \mathrm{~nm}$ (e.g., mycosporine-like amino acids) required a value of 1.5 to adequately identify and fit these

519 pigments. For spectra that did not contain a significant absorption signal below $400 \mathrm{~nm}$, the shape 520 of the spectra here is predominantly exponential. If a Gaussian component is erroneously assigned

521 in this spectral region, as in the example spectra in Figs. 2 and 3, the curve can be minimized in

522 Step 8 by fitting an adjusted exponential to $\mathrm{a}_{\mathrm{t}-\mathrm{w}}(\lambda)$. This adjustment is allowable within the 523 constraints provided and provides for consistent and stable solutions, since no Gaussian 524 components are dropped. This approach and the empirical values used best fit our global dataset, 525 but adjusting empirical values to a regional value is quite easy within the code available online 526 (Section 2.2.2).

\section{$527 \quad 4.2$ Gaussian Decomposition Approaches}

528 Gaussian component location was consistent between observed $\mathrm{a}_{\mathrm{ph}}(\lambda)$ and DAISEA output

529 (Fig. 7). We did not utilize Gaussian components to estimate the final $\mathrm{a}_{\mathrm{ph}}(\lambda)$ output, as we found 530 that a smoothed residual of $\mathrm{a}_{\mathrm{t}-\mathrm{w}}(\lambda)-\mathrm{a}_{\mathrm{dg} \_ \text {est }}(\lambda)$ more accurately represented observed $\mathrm{a}_{\mathrm{ph}}(\lambda)$. This is 531 likely due to fitting fewer Gaussian components than needed to accurately model $\mathrm{a}_{\mathrm{ph}}(\lambda)$, as 532 DAISEA fits fewer peaks than alternate Gaussian decomposition schemes due to a difference in 
533 methodologies (Hoepffner and Sathyendranath 1993; Chase et al. 2013). These algorithms

534 typically identify pigments from first and second derivative analysis of an existing database of

535 phytoplankton spectra then assign windows around these points (typically 12 peaks). Our approach

536 focuses on identifying primary pigment features to best fit observed $\mathrm{a}_{\mathrm{t}-\mathrm{w}}(\lambda)$ without assuming the

537 locations of pigments, resulting in fewer identified peaks ( 7 peaks). There is potential to increase

538 the sensitivity of the peak finding step. Our focus was to retrieve $\mathrm{adg}_{\mathrm{dg}}(\lambda)$ and $\mathrm{a}_{\mathrm{ph}}(\lambda)$ accurately,

539 including spectral shape, rather than individually parameterizing phytoplankton pigments. It is

540 possible to utilize the $\mathrm{a}_{\mathrm{ph}}(\lambda)$ output in a separate Gaussian decomposition scheme, or other

541 approach that identifies phytoplankton pigments. However, it should be noted that derivative

542 analysis of the final $\mathrm{a}_{\mathrm{ph}}(\lambda)$ output, even after smoothing, resulted in more identified peaks than the

543 observed $\mathrm{a}_{\mathrm{ph}}(\lambda)$ using our scheme. This is very likely due to the inclusion of chromophores in $\mathrm{ag}_{\mathrm{g}}(\lambda)$

544 and $\mathrm{a}_{\mathrm{d}}(\lambda)$ that result in deviations from the typical exponential expression used to model these

545 parameters, features visibly apparent in many of the $\mathrm{a}_{\mathrm{dg}}(\lambda)$ spectra. While often overlooked, these

546 features have been recognized for some time (Babin et al. 2003; Schwarz et al. 2002) and a recent

547 methodology for fitting these peaks provides a means of both quantifying them and more

548 accurately modeling the underlying exponential signal (Catalá et al. 2016; Massicotte and

549 Markager 2016; Grunert et al. 2018). This approach is useful for in situ data, but not practical for

550 our proposed methodology and likely a non-factor when considering $\mathrm{at}_{\mathrm{t}-\mathrm{w}}(\lambda)$ derived from satellite

$551 \mathrm{R}_{\mathrm{rs}}(\lambda)$.

552

\section{5. Conclusions}

554 We show that across most optical conditions considered, DAISEA can accurately estimate

$555 a_{d g}(\lambda), S_{d g}$ and $a_{p h}(\lambda)$ magnitude and spectral features for all water types where $\% a_{p h}(440)>10$. 
556 We parameterized the percent of $\mathrm{a}_{\mathrm{dg}}(\lambda)$ and $\mathrm{a}_{\mathrm{ph}}(\lambda)$ estimates that were retrievable by comparing

557 the signal observed for one IOP to the difference between estimated and observed values obtained

558 for the other IOP. Consistent with the general accuracy of DAISEA, primary features (i.e., 559 chlorophyll-a absorption peaks) of $\mathrm{a}_{\mathrm{ph}}(\lambda)$ were retrievable for greater than $80 \%$ of spectra across

560 environments where $\% \mathrm{a}_{\mathrm{ph}}(440)>10 ; \mathrm{a}_{\mathrm{dg}}(\lambda)$ was retrievable for at least $80 \%$ of spectra from 350 -

$561650 \mathrm{~nm}$ when $\% \mathrm{a}_{\mathrm{ph}}(440)<70$. NRMSD metrics suggest strong algorithm performance across most

562 optical variability from $350-650 \mathrm{~nm}$. Algorithm bias shows a tendency to overestimate $\mathrm{a}_{\mathrm{ph}}(\lambda)$ when

$563 \% \mathrm{a}_{\mathrm{ph}}(440)<40$ and to underestimate $\mathrm{a}_{\mathrm{ph}}(\lambda)$ when $\% \mathrm{a}_{\mathrm{ph}}(440)>60$.

564 Currently, coincident hyperspectral measurements of $R_{r s}(\lambda), b_{b p}(\lambda), a_{p h}(\lambda), a_{d}(\lambda)$ and $a_{g}(\lambda)$

565 observed down to a minimum wavelength of $350 \mathrm{~nm}$, the proposed lower wavelength limit of

566 PACE, are quite uncommon relative to coincident measurements at wavelengths $\geq 400 \mathrm{~nm}$. This,

567 along with limited hyperspectral inversion approaches free of spectral bias, limited our ability to

568 fully assess how well DAISEA will perform in the context of a top-down spectral deconvolution

569 approach. Despite empirical schemes for separation of $\mathrm{a}_{\mathrm{dg}}(\lambda)$ and $\mathrm{S}_{\mathrm{dg}}$ into the component parts

570 (NAP and CDOM; e.g., Dong et al. 2013), we did not pursue separation here. Considering current

571 algorithm performance, we anticipate that a well-performing scheme to separate $\operatorname{adg}_{\mathrm{dg}}(\lambda)$ into its

572 component parts will allow for appropriate resolution in $S_{\mathrm{g}}$ to estimate source and degradation

573 state of CDOM in the surface ocean. 


\section{Acknowledgements}

575 We gratefully acknowledge contributors to the SeaBASS data set (https://seabass.gsfc.nasa.gov/).

576 Thank you to Piotr Kowalczuk, Frédéric Mélin and two anonymous reviewers for comments that

577 greatly improved the final version of this manuscript. Algorithm development was funded by a 578 NASA Earth and Space Science Fellowship awarded to Grunert.

579

580 


\section{References}

Andrew, A.A., Del Vecchio, R., Subramaniam, A., \& Blough, N.V. (2013). Chromophoric dissolved organic matter (CDOM) in the Equatorial Atlantic Ocean: Optical properties and their relation to CDOM structure and source. Marine Chemistry, 148, 33-43

Babin, M., Stramski, D., Ferrari, G.M., Claustre, H., Bricaud, A., Obolensky, G., \& Hoepffner, N. (2003). Variations in the light absorption coefficients of phytoplankton, nonalgal particles, and dissolved organic matter in coastal waters around Europe. Journal of Geophysical Research, 108

Behrenfeld, M.J., Hu, Y., Hostetler, C.A., Dall'Olmo, G., Rodier, S.D., Hair, J.W., \& Trepte, C.R. (2013). Space-based lidar measurements of global ocean carbon stocks. Geophysical Research Letters, 40, 4355-4360

Behrenfeld, M.J., Hu, Y., O’Malley, R.T., Boss, E.S., Hostetler, C.A., Siegel, D.A., Sarmiento, J.L., Schulien, J., Hair, J.W., Lu, X., Rodier, S., \& Scarino, A.J. (2016). Annual boombust cycles of polar phytoplankton biomass revealed by space-based lidar. Nature Geoscience, 10, 118-122

Bracher, A., Vountas, M., Dinter, T., Burrows, J.P., Rüttgers, R., \& Peeken, I. (2009). Quantitative observation of cyanobacteria and diatoms from space using PhytoDOAS on SCIAMACHY data. Biogeosciences, 6, 751-764

Brando, V., Dekker, A., Park, Y.J., \& Schroeder, T. (2012). Adaptive semianalytical inversion of ocean color radiometry in optically complex waters. Appl Opt, 51

Bricaud, A., Babin, M., Morel, A., \& Claustre, H. (1995). Variability in the chlorophyll-specific absorption coefficients of natural phytoplankton: Analysis and parameterization. Journal of Geophysical Research, 100, 13,321-313,332

Bricaud, A., \& Morel, A. (1986). Light attenuation and scattering by phytoplanktonic cells: a theoretical modeling. Appl Opt, 25, 571-580

Bricaud, A., Morel, A., \& Prieur, L. (1983). Optical efficiency factors of some phytoplankters. Limnology \& Oceanography, 28, 816-832

Cael, B.B., \& Boss, E. (2017). Simplified model of spectral absorption by non-algal particles and dissolved organic materials in aquatic environments. Opt Express, 25, 25486-25491

Catalá, T.S., Reche, I., Ramón, C.L., López-Sanz, À., Álvarez, M., Calvo, E., \& ÁlvarezSalgado, X.A. (2016). Chromophoric signatures of microbial by-products in the dark ocean. Geophysical Research Letters, 43, 7639-7648

Chang, G.C., \& Dickey, T.D. (2004). Coastal ocean optical influences on solar transmission and radiant heating rate. Journal of Geophysical Research, 109

Chase, A., Boss, E., Zaneveld, R., Bricaud, A., Claustre, H., Ras, J., Dall'Olmo, G., \& Westberry, T.K. (2013). Decomposition of in situ particulate absorption spectra. Methods in Oceanography, 7, 110-124

Chase, A.P., Boss, E., Cetinić, I., \& Slade, W. (2017). Estimation of Phytoplankton Accessory Pigments From Hyperspectral Reflectance Spectra: Toward a Global Algorithm. Journal of Geophysical Research: Oceans, 122, 9725-9743

Ciotti, A.M., Lewis, M., \& Cullen, J.J. (2002). Assessment of the relationship between dominant cell size in natural phytoplankton communities and the spectral shape of the absorption coefficient. Limnology \& Oceanography, 47, 404-417 
Cory, R.M., \& Kling, G.W. (2018). Interactions between sunlight and microorganisms influence dissolved organic matter degradation along the aquatic continuum. Limnology and Oceanography Letters, 3, 102-116

Danhiez, F., Vantrepotte, V., Cauvin, A., Lebourg, E., \& Loisel, H. (2017). Optical properties of chromophoric dissolved organic matter during a phytoplankton bloom. Implication for DOC estimates from CDOM absorption. Limnology and Oceanography, 62, 1409-1425

Dutkiewicz, S., Hickman, A.E., Jahn, O., Gregg, W.W., Mouw, C.B., \& Follows, M.J. (2015). Capturing optically important constituents and properties in a marine biogeochemical and ecosystem model. Biogeosciences, 12, 4447-4481

D’Errico, J. (2005). Surface Fitting using gridfit. In. (https://www.mathworks.com/matlabcentral/fileexchange/8998-surface-fitting-usinggridfit): MATLAB Central File Exchange

Fichot, C.G., \& Benner, R. (2011). A novel method to estimate DOC concentrations from CDOM absorption coefficients in coastal waters. Geophysical Research Letters, 38

Fichot, C.G., Benner, R., Kaiser, K., Shen, Y., Amon, R.M.W., Ogawa, H., \& Lu, C.-J. (2016). Predicting Dissolved Lignin Phenol Concentrations in the Coastal Ocean from Chromophoric Dissolved Organic Matter (CDOM) Absorption Coefficients. Frontiers in Marine Science, 3

Fichot, C.G., Kaiser, K., Hooker, S.B., Amon, R.M., Babin, M., Belanger, S., Walker, S.A., \& Benner, R. (2013). Pan-Arctic distributions of continental runoff in the Arctic Ocean. Sci Rep, 3, 1053

Grunert, B.K., Mouw, C.B., \& Ciochetto, A.B. (2018). Characterizing CDOM Spectral Variability Across Diverse Regions and Spectral Ranges. Global Biogeochemical Cycles, 32, 57-77

Hansell, D.A., Carlson, C.A., Repeta, D.J., \& Schlitzer, R. (2009). Dissolved organic matter in the ocean: A controversy stimulates new insights. Oceanography, 22, 202-211

Helms, J.R., Stubbins, A., Perdue, E.M., Green, N.W., Chen, H., \& Mopper, K. (2013). Photochemical bleaching of oceanic dissolved organic matter and its effect on absorption spectral slope and fluorescence. Marine Chemistry, 155, 81-91

Helms, J.R., Stubbins, A., Ritchie, J.D., Minor, E.C., Kieber, D.J., \& Mopper, K. (2008). Absorption spectral slopes and slope ratios as indicators of molecular weight, source, and photobleaching of chromophoric dissolved organic matter. Limnology and Oceanography, 53, 955-969

Hieronymi, M., Müller, D., \& Doerffer, R. (2017). The OLCI Neural Network Swarm (ONNS): A Bio-Geo-Optical Algorithm for Open Ocean and Coastal Waters. Frontiers in Marine Science, 4

Johnsen, G., Nelson, N., Jovine, R.V.M., \& Prezelin, B. (1994). Chromoprotein- and pigment dependent modeling of spectral light absorption in two dinoflagellates, Prorocentrum minimum and Heterocapsa pygmaea. Marine Ecology Progress Series, 114, 245-258

Kim, G.E., Gnanadesikan, A., \& Pradal, M.-A. (2016). Increased Surface Ocean Heating by Colored Detrital Matter (CDM) Linked to Greater Northern Hemisphere Ice Formation in the GFDL CM2Mc ESM. Journal of Climate, 29, 9063-9076

Lee, Z., Carder, K.L., Arnone, R., \& He, M. (2007). Determination of primary spectral bands for remote sensing of aquatic environments. Sensors, 7, 3428-3441 
Lee, Z., Carder, K.L., \& Arnone, R.A. (2002). Deriving inherent optical properties from water color: a multiband quasi-analytical algorithm for optically deep waters. Appl Opt, 41, $5755-5772$

Mannino, A., Novak, M.G., Hooker, S.B., Hyde, K., \& Aurin, D. (2014). Algorithm development and validation of CDOM properties for estuarine and continental shelf waters along the northeastern U.S. coast. Remote Sensing of Environment, 152, 576-602

Mentges, A., Feenders, C., Seibt, M., Blasius, B., \& Dittmar, T. (2017). Functional Molecular Diversity of Marine Dissolved Organic Matter Is Reduced during Degradation. Frontiers in Marine Science, 4, 194

Morel, A., \& Prieur, L. (1977). Analysis of variations in ocean color. Limnology \& Oceanography, 22, 709-722

Mouw, C.B., Greb, S., Aurin, D., DiGiacomo, P.M., Lee, Z., Twardowski, M., Binding, C., Hu, C., Ma, R., Moore, T., Moses, W., \& Craig, S.E. (2015). Aquatic color radiometry remote sensing of coastal and inland waters: Challenges and recommendations for future satellite missions. Remote Sensing of Environment, 160, 15-30

Mélin, F., \& Vantrepotte, V. (2015). How optically diverse is the coastal ocean? Remote Sensing of Environment, 160, 235-251

Nelson, N.B., Siegel, D.A., Carlson, C.A., \& Swan, C.M. (2010). Tracing global biogeochemical cycles and meridional overturning circulation using chromophoric dissolved organic matter. Geophysical Research Letters, 37

Ogawa, H., Amagai, Y., Koike, I., Kaiser, K., \& Benner, R. (2001). Production of refractory dissolved organic matter by bacteria. Science, 292, 917-920

Riedel, T., \& Dittmar, T. (2014). A method detection limit for the analysis of natural organic matter via Fourier transform ion cyclotron resonance mass spectrometry. Analytical chemistry, 86, 8376-8382

Sadeghi, A., Dinter, T., Vountas, M., Taylor, B., Altenburg-Soppa, M., \& Bracher, A. (2012). Remote sensing of coccolithophore blooms in selected oceanic regions using the PhytoDOAS method applied to hyper-spectral satellite data. Biogeosciences, 9, 2127 2143

Schwarz, J.N., Kowalczuk, P., Kaczmarek, S., Cota, G., Mitchell, B.G., Kahru, M., Chavez, F.P., Cunningham, A., McKee, D., Gege, P., Kishino, M., Phinney, D.A., \& Raine, R. (2002). Two models for absorption by coloured dissolved organic matter (CDOM). Oceanologia, 44, 209-241

Stedmon, C.A., \& Markager, S. (2003). Behaviour of the optical properties of coloured dissolved organic matter under conservative mixing. Estuarine, Coastal and Shelf Science, 57, 973979

Trochta, J.T., Mouw, C.B., \& Moore, T.S. (2015). Remote sensing of physical cycles in Lake Superior using a spatio-temporal analysis of optical water typologies. Remote Sensing of Environment, 171, 149-161

Vandermeulen, R.A., Mannino, A., Neeley, A., Werdell, J., \& Arnone, R. (2017). Determining the optimal spectral sampling frequency and uncertainty thresholds for hyperspectral remote sensing of ocean color. Opt Express, 25, A785-A797

Vantrepotte, V., Danhiez, F.P., Loisel, H., Ouillon, S., Meriaux, X., Cauvin, A., \& Dessailly, D. (2015). CDOM-DOC relationship in contrasted coastal waters: implication for DOC retrieval from ocean color remote sensing observation. Opt Express, 23, 33-54 
Wang, G., Lee, Z., Mishra, D.R., \& Ma, R. (2016). Retrieving absorption coefficients of multiple phytoplankton pigments from hyperspectral remote sensing reflectance measured over cyanobacteria bloom waters. Limnology and Oceanography: Methods, 14, 432-447

Wang, G., Lee, Z., \& Mouw, C. (2017). Multi-Spectral Remote Sensing of Phytoplankton Pigment Absorption Properties in Cyanobacteria Bloom Waters: A Regional Example in the Western Basin of Lake Erie. Remote Sensing, 9

Wang, G., Lee, Z., \& Mouw, C. (2018). Concentrations of Multiple Phytoplankton Pigments in the Global Oceans Obtained from Satellite Ocean Color Measurements with MERIS. Applied Sciences, 8

Wang, P., Boss, E., \& Roesler, C.S. (2005). Uncertainties of inherent optical properties obtained from semianalytical inversions of ocean color. Appl Opt, 44, 4074-4085

Werdell, P.J., Bailey, S.W., Fargion, G.S., Pietras, C., Knobelspiesse, K.D., Feldman, G.C., \& McClain, C.R. (2003). Unique data repository facilitates ocean color satellite validation. EOS Trans. AGU, 84, 377

Werdell, P.J., McKinna, L.I.W., Boss, E., Ackleson, S.G., Craig, S.E., Gregg, W.W., Lee, Z., Maritorena, S., Roesler, C.S., Rousseaux, C.S., Stramski, D., Sullivan, J.M., Twardowski, M.S., Tzortziou, M., \& Zhang, X. (2018). An overview of approaches and challenges for retrieving marine inherent optical properties from ocean color remote sensing. Progress in Oceanography, 160, 186-212

Werdell, P.J., Proctor, C.W., Boss, E., Leeuw, T., \& Ouhssain, M. (2013). Underway sampling of marine inherent optical properties on the Tara Oceans expedition as a novel resource for ocean color satellite data product validation. Methods in Oceanography, 7, 40-51

Wetzels, R., \& Wagenmakers, E.J. (2012). A default Bayesian hypothesis test for correlations and partial correlations. Psychon Bull Rev, 19, 1057-1064

Xing, X., Morel, A., Claustre, H., D'Ortenzio, F., \& Poteau, A. (2012). Combined processing and mutual interpretation of radiometry and fluorometry from autonomous profiling BioArgo floats: 2. Colored dissolved organic matter absorption retrieval. Journal of Geophysical Research: Oceans, 117

Zhao, Z., Gonsior, M., Luek, J., Timko, S., Ianiri, H., Hertkorn, N., Schmitt-Kopplin, P., Fang, X., Zeng, Q., \& Jiao, N. (2017). Picocyanobacteria and deep-ocean fluorescent dissolved organic matter share similar optical properties. Nature communications, 8, 15284 
747 Tables

748 Table 1.

749 Median and distribution of observed $S_{d g}\left(1^{\text {st }}\right.$ and $3^{\text {rd }}$ quartile $)$ delineated by percent $a_{p h}(440)$

750 contribution. Relative accuracy of estimated $S_{d g}$ is presented as the median and distribution of

751 absolute difference (estimated $S_{d g}-$ observed $S_{d g}$ ).

\begin{tabular}{|c|c|c|c|c|c|c|}
\hline \multicolumn{4}{|c|}{ Observed $S_{d g}\left(\mathrm{~nm}^{-1}\right)$} & \multicolumn{3}{|c|}{ Relative estimated $S_{d g}$ accuracy $\left(\mathrm{nm}^{-1}\right)$} \\
\hline $\mathbf{1}^{\text {st }}$ quartile & Median & $3^{\text {rd }}$ quartile & $a_{p h}(440)$ & $1^{\text {st }}$ quartile & Median & $3^{\text {rd }}$ quartile \\
\hline 0.0146 & 0.0153 & 0.0161 & $<10 \%$ & -0.0003 & -0.0001 & -0.0001 \\
\hline 0.0143 & 0.0165 & 0.0176 & $10-20 \%$ & -0.0015 & -0.0010 & +0.0004 \\
\hline 0.0141 & 0.0156 & 0.0175 & $20-30 \%$ & -0.0010 & -0.0001 & +0.0013 \\
\hline 0.0127 & 0.0142 & 0.0159 & $30-40 \%$ & -0.0015 & +0.0001 & +0.0017 \\
\hline 0.0126 & 0.0140 & 0.0150 & $40-50 \%$ & -0.0024 & -0.0005 & +0.0016 \\
\hline 0.0128 & 0.0146 & 0.0160 & $50-60 \%$ & -0.0018 & -0.0003 & +0.0021 \\
\hline 0.0120 & 0.0138 & 0.0167 & $60-70 \%$ & -0.0024 & -0.0007 & +0.0005 \\
\hline 0.0139 & 0.0191 & 0.0211 & $>70 \%$ & -0.0037 & -0.0022 & -0.0002 \\
\hline
\end{tabular}




\section{Figure Captions}

754 1. Locations of spectra utilized in the (a) training dataset and (b) test dataset where color and size represent spectra grouped by varying $\mathrm{a}_{\mathrm{ph}}(440)$ percent contribution to total non-water absorption.

2. Schematic and figures illustrating primary steps for the Gaussian decomposition algorithm. This schematic is provided to aid in visualizing and organizing the steps detailed in the accompanying text (Section 2.2). Each figure illustrates the step as indicated for an through all the steps (e.g., Fig. 2c shows a successful first guess, while some spectra required an iteration at this step).

3. Algorithm output for the example spectra depicted in Fig. 2. Gray dashed lines indicate the estimated (a) $\mathrm{a}_{\mathrm{dg}}(\lambda)$ and (b) $\mathrm{a}_{\mathrm{ph}}(\lambda)$ used as input into the least squares Gaussian decomposition of observed $\mathrm{a}_{\mathrm{t}-\mathrm{w}}(\lambda)$ and black dashed lines indicate the respective observed IOP. For (a) and (b), respective colored lines display algorithm output. For (c), the brown line represents $a_{d g}(\lambda)$ algorithm output, the green line represents $a_{d g}(\lambda)+a_{p h}(\lambda)$ algorithm output and the black line with circles indicates observed $\mathrm{a}_{\mathrm{t}-\mathrm{w}}(\lambda)$. This example shows how a Gaussian component can be fitted to the residuals derived from Step 5 (Fig. 2), but is minimized due to a better fit of observed $\mathrm{a}_{\mathrm{t}-\mathrm{w}}(\lambda)$ with an exponential curve. non-water absorption (indicated by color, from tan to dark green). Each plot corresponds to (a) percent retrievable $a_{p h}(\lambda)$, (b) percent retrievable $a_{d g}(\lambda)$, (c) $a_{p h}(\lambda) \%$ NRMSD, (d) $\mathrm{a}_{\mathrm{dg}}(\lambda) \% \mathrm{NRMSD},(\mathrm{e}) \mathrm{a}_{\mathrm{ph}}(\lambda)$ bias $\left(\mathrm{a}_{\mathrm{dg}}(\lambda)\right.$ bias represented as inverse of each line) and (f) 
mean absolute difference for both $\mathrm{a}_{\mathrm{ph}}(\lambda)$ and $\mathrm{a}_{\mathrm{dg}}(\lambda)$ (equivalent value by nature of the

776 metric).

777 5. Mean performance of the algorithm for all test spectra within each group of spectra delineated by $\mathrm{a}_{\mathrm{ph}}(440)$ percent contribution to total non-water absorption relative to mean observed (a,c,e,g,i,k,m,o) $a_{\mathrm{ph}}(\lambda)$ and (b,d,f,h,j,l,n,p) $\mathrm{a}_{\mathrm{dg}}(\lambda)$. The number of spectra within each group was: $(a, b) n=286 ;(c, d) n=257 ;(e, f) n=303 ;(g, h) n=210 ;(i, j) n=146 ;(k, 1) n=89$; $(m, n) n=34 ;(o, p) n=28$.

782

6. (a) Unbiased absolute percent difference of $S_{\mathrm{dg}}$ for each grouping delineated by $\% \mathrm{a}_{\mathrm{ph}}(440)$, indicated by the color (see legend) and (b) distribution and relationship between observed and estimated $\mathrm{S}_{\mathrm{dg}}$, with marker color indicating $\% \mathrm{a}_{\mathrm{ph}}(440)$ and the dashed black line (--) representing the 1:1 line.

7. Distribution of identified peak locations for (a) observed $a_{\mathrm{ph}}(\lambda)$ and (b) $a_{\mathrm{ph}}(\lambda)$ estimated from $a_{t-w}(\lambda)$. Overall, identified peaks were quite consistent between the two signals displaying the strength of the scheme for initial estimates and constraints used for the Gaussian decomposition model.

8. A theoretical representation of varying spectral shape of $\mathrm{a}_{\mathrm{t}-\mathrm{w}}(\lambda)$ under varying contributions of $\mathrm{a}_{\mathrm{dg}}(\lambda)$ and $\mathrm{a}_{\mathrm{ph}}(\lambda)$. The base $\mathrm{a}_{\mathrm{dg}}(\lambda)$ and $\mathrm{a}_{\mathrm{ph}}(\lambda)$ spectra used for each curve are taken from measured spectra. We utilized this theoretical framework to develop the algorithm, namely understanding how changes in $\mathrm{a}_{\mathrm{ph}}(\lambda)$ percent contribution will inherently impact estimates of $S_{\mathrm{dg}}$, how this inherent bias is impacted by wavelengths used and how to assess whether $\mathrm{a}_{\mathrm{dg}}(\lambda)$ has been accurately retrieved from $\mathrm{a}_{\mathrm{t}-\mathrm{w}}(\lambda)$ free of an empirical relationship.

9. Relationship between $\mathrm{a}_{\mathrm{t}-\mathrm{w}}(555) / \mathrm{a}_{\mathrm{t}-\mathrm{w}}(680)$ and $\mathrm{a}_{\mathrm{ph}}(440)$ contribution for the (a) training 
the red line, blue points indicate fitted data and gray points indicate values excluded from model fitting $\left(\mathrm{r}^{2}=0.91, \mathrm{RMSD}=0.068\right)$. Outliers were defined as $1.5 \cdot 1^{\text {st }} / 3^{\text {rd }}$ quartile and were used to remove the influence of the large spread in data points with $\% \mathrm{a}_{\mathrm{ph}}(440)<10$, as these points represented nearly $25 \%$ of the dataset. (b) Test dataset points relative to the piecewise exponential relationship derived from the training dataset, displaying the primary weakness in empirical relationships $\left(\mathrm{r}^{2}=0.58, \mathrm{RMSD}=0.110\right)$. 